\title{
Las prácticas retóricas y hermenéuticas de sí
}

\author{
ÁNGEL GABILONDO
}

\section{UN MODO DE PROCEDER Y UN MODO DE SER}

Tanto la retórica como la hermenéutica se caracterizan por «una cierta ambigüedad de una pretensión científica, determinada en parte por la relación con la práctica. Porque es evidente que la retórica no es una simple teoría de las formas del discurso y de los medios de persuasión, sino que se puede desarrollar partiendo de una capacidad natural para la destreza práctica» 1 . Esta destreza no es pura habilidad, es una manera de hacer, que no se mostrará al margen de un modo de ser ${ }^{2}$. Puede adop-

I Hans-Georg Gadamer, «Rhetorik, Hermeneutik und Ideologiekritik. Metakritische Erörterungen zu Wahrheit und Methode», en Hermeneutik II. Wahrheit und Methode. Ergänzungen. Register (WM II), Gesammelte Werke (GW), Tubinga, Mohr, 1985-1995, 10 vols., t. 2, 19932 (1986), pp. 232-250, p. 234 (trad. cast. Salamanca, Sígueme, 1984, VM II, 1992, pp. 225-265, p. 227).

2 Para Gadamer, estamos en lo que forma parte de la conducta básica de la existencia humana, de aquello que todo individuo es o puede hacer. Al estudiar la relación entre retórica y hermenéutica y su desarrollo subraya que «tampoco el arte de la interpretación y de la comprensión es una destreza específica que se puede estudiar y aprender para llegar a ser una especie de intérprete profesional. Pertenece al ser humano como tal». «Rhetorik und Hermeneutik», WM II, pp. 276-291, p. 291 (trad. cast. VM II, pp. 267-281, p. 281). 
tar la forma de un despertar, también de los propios afectos, pero es, a su vez, una puesta en juego de determinadas posibilidades. Esas maneras llegan a ser verdaderos estilos de existencia y formas de vida que corresponden a una efectiva puesta en cuestión de lo que se es. Es en tal contexto en el que han de enmarcarse los procesos para 'desprenderse de sí mismo', para 'perder el rostro', no tanto como formas de una frivolidad en acción, sino como efectivo poder de la libertad, de la liberación inscrita en prácticas de libertad. No son estratagemas, son estrategias para conducir la propia vida y la de los otros. Y esta conducción es también autogobierno.

Conviene recordar, en todo caso, que hay una cierta inapropiabilidad de uno mismo, que no habla de la inadecuación de una conducta, sino de la 'materialidad' de lo que nos teje, que impide su absoluta posesión. Ante ella se precisa una determinada vacancia que adopta la forma de una actividad múltiple que exige que se pierda tiempo y no se escatime esfuerzo para 'hacerse a sí mismo'. Y aquí radica la cuestión. No estamos ante el puro juego del genio y de la libertad, ni siquiera ante un mero juego de fuerzas ${ }^{3}$. Se trata de hacer brotar los límites y las necesidades de una práctica que no se reduce a las actividades que se realizan, sino que convoca, a la par, a la aparición de toda una serie de prácticas en su espesor y en su complejidad. Y más aún, el asunto es poblematizar los ejes de la constitución de nuestra experiencia. Por eso, consistir en estar llamados a intervenir es más que una mera manipulación de lo que hay. Es la experiencia de estar involucrado. No sólo de hablar, sino de 'ser palabra', capaces de decisión, la de aquellos que también se juegan lo que son en lo que dicen, que se sienten comprometidos por ello y que, sin embargo, no se consideran plenos poseedores de lo que se dice. Quizá por eso una de las tareas que constituyen de modo decisivo esta serie de prácticas de libertad podría caracterizarse como la necesidad de hacer que algo hable de nuevo, que vuelva al significar y que sea capaz de propiciar un espacio de comunicación. Precisamente por ello, el esquema del diálogo resulta fecundo si se utiliza correctamente: en el intercambio de las fuerzas y en la confrontación de las opiniones se construye una comunidad que transciende al individuo y al grupo al que ésta pertenece ${ }^{4}$. Así cabe destacar que «el acuerdo presupone siempre la so-

3 «El juego de las fuerzas se complementa con el juego de las creencias, argumentaciones y experiencias». «Replik zu Hermeneutik und Ideologiekritik», WM II, pp. 251-275, p. 275 (trad. cast. VM II, pp. 243-265, p. 265).

4 Hans-Georg Gadamer, «Replik zu Hermeneutik und Ideologiekritik», WM II, pp. 251-275, p. 275 (trad. cast. VM II, pp. 243-265, p. 265). 
lidaridad» 5 . En esta perspectiva, la palabra 'diálogo' no se reduce a un mero intercambio, es una efectiva creación de espacios, también de conversación, en los que uno se juega lo que podría considerarse propio.

Cuando se recuerda que la Retórica de Aristóteles no se reduce a una teoría de la elocución, ni se limita a una teoría de la composición del discurso, sino que es también una teoría de la argumentación, se está diciendo algo más: que hablar no es simplemente demostrar. Se reclama un determinado probar y probarse. El ensayo no es una simple relación de esforzados intentos. Se corresponde con un suceder que no se impone sin cuestionar o sin reclamar respuesta, un suceder que pide, desconcertadamente quizá, responsabilidad: un suceder con alguien, con otros. Dejar hablar y contar con otros se hacen cargo de una serie de prácticas de libertad en las que desprenderse de sí mismo es una forma de escucha. Argumentar, además de ofrecer buenas razones capaces de poner en acción, de mover, de motivar, es un proceso de búsqueda. Dicha búsqueda, sin duda, lo es también de las formas y artificios de la expresión, pero no es la satisfacción en simples técnicas expresivas. Incluso éstas son también interpretación.

$\mathrm{Si}$ argumentar tiene que ver con persuadir es en la medida en que nos encontramos en la necesidad de una permanente búsqueda; en efecto, de buenos argumentos. Pero no sólo. Búsqueda de un espacio en el que vivir con otros, búsqueda de cuanto anime un vivir y haga posible un esperar -que no es acopio de expectativas-, un desear-que no es simple apetencia de algo- un respirar. Búsqueda de un modo de ser, quizá de una palabra justa, justificada, y de la fuerza para preferir algo por encontrarlo verosímil, plausible, probable. El dominio de la argumentación es el de 'las acciones de la vida', un dominio en el que apenas disponemos de evidencias lógicas y de certezas objetivas, en el que nos movemos en el orden de lo verosímil6. En dicho contexto, la llamada teoría del discurso no demostrativo reclama el amparo de una hermenéutica sin voluntad de acaparar los espacios del pensar. De este modo, nuestros recursos, los del arte y las técnicas de interpretación, no sólo están tomados en buena medida de la retórica ${ }^{7}$, es que responden a una misma necesidad, prácticamente a un destino, el que propicia y reclama libertad. En esta dirección han de considerarse la retórica y la herme-

$5 \quad$ Ibid., p. 269 (trad. cast. p. 260).

6 Olivier Reboul, «La figure et l'argument», en Michel Meyer (ed.), De la Métaphysique à la Rhétorique, Univ. de Bruxelles, 1986, pp. 175-187, p. 187.

7 Hans-Georg Gadamer, «Rhetorik, Hermeneutik und Ideologiekritik», loc. cit., p. 236 (trad. cast. p. 229). 
néutica como «formas concretas de vida» 8 , que responden a una determinada poética de la existencia como recreación.

Tener que ver con alguien y tener que ver con el asunto, que se consideran como condición hermenéutica, y que incluso constituyen la precomprensión, abren de hecho la comprensión, cuyo carácter es siempre productivo ${ }^{9}$ y afecta a la relación general de los seres humanos entre sí con el mundo. En este contexto, comprender no es deducir una cosa de otra, no es algo metodológico que responde a un determinado ideal de raciocinio lógico, sino que, en contraste con dicho ideal y dada la circularidad entre el sujeto que comprende y lo que se comprende, es un modo de ser en el mundo, no una mera actitud para determinados objetos de conocimiento. De ahí que Heidegger hable de una hemenéutica de la facticidad, en la que el tema de la investigación hermenéutica es en cada ocasión el existir propio. Así, en este planteamiento, confiarse al lenguaje es entrar en diálogo con otros pensantes y con los que piensan de otro modo, no el entregarse a un concepto ya definido y dado de antemano. Tanto como se reclama un diálogo vivo, se hace la experiencia de que lo dado es lo producido, lo vivido.

Desde estas consideraciones nos importa subrayar el arte de existir, ese saber de la existencia finita acerca de lo posible, esa verdadera producción que exige, en cierto modo, suspender la propia vida. Tal suspensión que, como señalamos, es tanto como aprender a desprenderse de sí mismo, no es un huir de sí. Si algo nos llama la atención (y ésta es una de las condiciones hermenéuticas), nos sentimos efectivamente llamados, también a una suspensión de juicios. Pero toda suspensión de juicios, comenzando por los prejuicios, posee la estructura lógica de la pregunta ${ }^{10}$. Entonces, huir no es escapar, sino una fuga permanente, fuga precisamente de esa forma de huida que consiste en creer que ya se ha llegado, que no hay más posibilidades o que no pueden jugarse (de nuevo, juego no sólo de fuerzas) de otro modo. Cuestionarse es cuestionar los propios prejuicios, que también lo son para uno lo que el otro o un texto dice. No es pura eliminación, es la aclaración que consiste en hacer uso de tales prejuicios, esto es, contrastarlos con otros y procurar (que es un cuidar) que se expliciten nuevos. Con ello, se subraya que el

8 Hans-Georg Gadamer, «Replik zu Hermeneutik und Ideologiekritik», loc. cit., p. 274 (trad. cast. p. 264).

9 Hans-Georg Gadamer, Hermeneutik I. Wahrheit und Methode. Grundzüge einer philosophischen Hermeneutik (WM I), t. 1, p. 366 (trad. cast. Salamanca, Sígueme, 1984, VM I, p. 301).

10 Hans-Georg Gadamer, «Von Zirkel des Verstehens», WM II, pp. 57-64, p. 64 (trad. cast. pp. 63-70, p. 69). 
concepto de juego va unido, en efecto, al de pluralidad de fuerzas opuestas en una determinada unidad.

Hemos de entender, por tanto, ese desprenderse de sí mismo como una permanente creación de nosotros mismos que comporta, a la par, la atención a los discursos como acontecimientos históricos. Por eso, no se trata sólo de comprender lo histórico del acontecimiento, sino de hacerse cargo de lo histórico del comprender. Y, efectivamente histórico. Algo, en verdad, ocurre, y sucede como alguien. Somos libres y capaces, no sólo de constituirnos como sujetos de nuestro saber o de ejercer o padecer relaciones de poder, sino de habernos constituido en sujetos morales de nuestras acciones. Esta actitud, este éthos, implica vivir una vida filosófica, «en la que la crítica de lo que somos es, a la vez, un análisis histórico de los límites que nos han establecido y un examen de su franqueamiento posible» 1 . Ello conlleva un adecuado cuidado de sí que es cuidado del propio vivir filosófico, un modo de proceder filosófico que es todo un trabajo, una manera de conducirse, un modo de hacer, un modo de ser y una manera de comportarse: la libertad como éthos ${ }^{12}$.

Tal planteamiento conlleva el reconocimiento de que cabe lo discutible y lo problemático. No nos limitamos a ser autores. La lógica de la pregunta llega a adoptar la forma de relación de interrogación. El ensayo es búsqueda y exige ponerse en cuestión y poner en cuestión la propia palabra; mejor, ponerse en la cuestión del ser de la palabra. Lo que comporta innegables riesgos. La creación es retórica y hermenéutica invención. Y crítica; para empezar, la de una situación problemática y efectivamente crítica.

Con esta perspectiva, no han de olvidarse los puntos de referencia. Por ejemplo, los textos pueden considerarse como fases en el proceso de comprensión, algo que, en tanto que fijado y aislado ${ }^{13}$, posee aún un nivel de abstracción que, en su ejecución, se concreta. Por eso, comprender lo que el texto dice es tanto como hacer que vuelva a hablar. Para ello ha de ser legible, a fin de que se pueda hacer hablar de nuevo al texto fijado ${ }^{14}$.

II Michel Foucault, «Qu'est-ce que les Lumières?», Dits et écrits (1954-1988) (DE), París, Gallimard, 1994, 4 t., t. IV, (1980-1988), pp. 562-578, pp. 574-575.

12 Michel Foucault, «L'éthique du souci de soi comme pratique de la liberté», DE, t. IV, pp. 708-729, p. 714.

13 Paul Ricoeur, «Qu'est-ce qu'un texte?», Du texte à l'action. Essais d'herméneutique II, París, Seuil, 1986, pp. 137-159, p. 137 (trad. cast. Historia y narratividad, Barcelona, Paidós, pp. 59-81, p. 59).

14 Hans-Georg Gadamer, «Über das Lesen von Bauten und Bilder», Ästhetik und Poetik I. Kunst als Aussage, GW, t. 8, 1993, pp. 331-338 (trad. cast. Estética y Hermenéutica, Madrid, Técnos, 1996, pp. 255-265). 
Esto otorga a la ejecución el carácter de algo otro que una mera puesta en práctica. Se trata de una práctica efectiva, de hacer que la acción prosiga, comprendiéndola. Eso reclama posición y composición. Y, además, una capacidad. Un volver a hacer adecuado, conveniente, convincente.

Consideradas así las cosas, las prácticas no son un aditamento o un condimento, sino una atención a las condiciones y a los procesos, a las discontinuidades de las trayectorias históricas. Las lecturas son siempre una práctica encarnada en gestos, espacios y costumbres; hay una historia de las formas de leer. Han de atenderse los discursos en su especificidad, inscritos en lugares y medios de su producción y con determinadas condiciones de posibilidad, relacionados con los principios de regularidad que los ordenan y los controlan e interrogados en sus modos de acreditación y de veracidad ${ }^{15}$. Aquí también habrá de recordarse que las historias no preexisten a su acaecer y que en ellas juegan de una manera decisiva los procedimientos de creatividad, las tareas de relación y de experiencia. Cobran así todo su alcance las prácticas de libertad. Si tantas veces hemos oído hablar de la necesidad del estudio del cuidado de sí, de la belleza de la propia vida, de la escritura de sí, de hacer de sí mismos, como verdaderos artífices, una obra de arte es porque, frente a una teoría a priori del sujeto, se reconoce la necesidad de procesos de constitución, frente a una idea del sujeto como sustancia, se reclama como forma, frente a una teoría previamente establecida, se abre paso la necesidad de considerarla a partir de determinadas prácticas. Prácticas y ejercicios responden a la consideración de alguien que es capaz de libertad, de elaborarse y de transformarse. Las prácticas de las que hablamos pueden conformar todo un conjunto, ser discursivas o no discursivas y constituir una auténtica problematización de todo nuestro comportamiento y actitudes que no se limita a identificar lo que uno es con lo que hace. La suspensión de la propia vida es, en efecto, la libertad con relación a lo que se hace, la crítica permanente de lo que somos. Se trata de buscar por dónde es «lo que es y cómo lo que es podría dejar de ser lo que es» 16 . Ese dejar de ser es un hacer ver. Tal tarea de la filosofía no consiste en descubrir lo que está oculto, sino en hacer visible lo que, precisamente, es visible; es decir, hacer aparecer lo que resulta tan próximo tan supuestamente inmediato, tan inmanentemente ligado a nosotros mismos

15 Roger Chartier, El mundo como representación. Historia cultural: entre práctica y representación, Barcelona, Gedisa, $3^{\mathrm{a}}$ reimp., 1996, pp. 53 y 61. 457, p. 449.

16 Michel Foucault, «Structuralisme et poststructuralisme», DE, t. IV, pp. 431- 
que, por ello, no lo percibimos. Este hacer visible lo invisible es reconocer lo que hay no sólo en lo invisible de algo que no se reduce a un puro ver, sino también lo que no se hace visible en lo visible.

Es como si alguien fuera tan uno mismo como lo que ya parece ocurrirle. Los estoicos destacan que lo que uno es no siempre está dentro de sí, sino en los logoi, los preceptos de los maestros. En este punto se enriquece la retórica y la hermenéutica de sí. Lo que uno es puede estar en la palabra de otros, en la tradición, en las lecturas, en la palabra del otro. Así se produce una cierta subjetivación del propio cuerpo, una incorporación de lo otro del cuerpo. Ello nos permitiría hablar de la necesidad de incorporar al ánima, el alma que forma parte de la constitución de sí mismo. Reconocer que uno está por venir, que es aquello hacia lo que va, que sus propias luchas y deseos procuran efectivos acontecimientos, por un lado, historiza la noción de sí y, por otro, deja en su lugar a las prácticas. No hablamos de procesos de interiorización, como si hubiera de buscarse en lo más profundo de uno su verdadero sí mismo. El cuidado de sí es una serie de prácticas y ejercicios que tratan de llegar a ganar lo que alguien puede llegar a ser. Incorporar ese poder ser supone un conjunto de tecnologías y de técnicas, de artes de la existencia, mediante los cuales cabe la posibilidad de venir a dar, a constituirse a sí mismo como sujeto.

Se ha producido, de este modo, una importante modificación. El ejercicio no es una mera repetición de actividad. Supone un saber, unido precisamente a dicho ejercicio, y esta unión es la tarea de inventar (también es un venir a dar, un invenire), una manera de ser, aquélla que responde a ese hacia en el que también consistimos. Las prácticas conllevan reglas, modos de hacer, convenciones. Más aún, lo que llamamos 'las cosas' y 'los hechos' son ya objetivaciones prácticas y no algo simplemente preexistente. Los modos de proceder llegan a ser modos de decir. Aprender a leerse a sí mismo es un ejercicio extremo y raro, también un ejercicio peligroso. Leerse no como algo ya dado, sino como una tarea de cuidado y constitución. Las prácticas no se reducen a discursos. Además de toda una historia de las modalidades de apropiación y de las modalidades de representación, que hacen que la significación dependa de las categorías y de los códigos y que llegue a producirse un campo de enunciados, que nos hacen depender de un pasado del que son huella, la atención a aquello que se nos transmite y a la par se nos entrega como posibilidad abierta llama a una producción y a una serie de operaciones. Este juego exige fuerza, incluso la de sobreponerse a sí mismo, la de comportarse como quien todavía supuestamente no se es, la de un modo que hace ser. Estos modos de transformarse a sí mismos, son intensidaes, modos del ser que se desea llegar a ser. 
Por ello, de la misma manera que resulta inadecuado reducir la retórica de sí a una serie de procedimientos o técnicas de elocución, o a la pura expresión cuidada de lo que ya se es, o a la pura reivindicación sin justificación, sin argumentación, incapaz de motivar, como si hablar fuera una actividad más entre otras y no lo que nos constituye con otros y nos ofrece la posibilidad de mundo y de ciudad, ahora lo discutible de las prácticas no es el mero aprendizaje de reglas de comportamiento, sino un efectivo ensayo y examen que transforma las relaciones de uno consigo mismo y con los otros. Estudiar modos de vida o elecciones de existencia o modos de regular la conducta o de fijarse medios y fines es hacerlo de las técnicas de sí. Entre dichas técnicas, la práctica de la palabra libre ocupa un lugar primordial, el de experiencia decisiva.

No se renuncia al desafío de producir un saber verdadero, de ser un discurso de verdad, de bien decir. No se reducirá a lo visible, atenderá a las formas, a la comprensión de las condiciones y formas de inteligibilidad histórica y no se limitará a contenido. Su funcionamiento y sus efectos, sus dispositivos, sus articulaciones y sus estrategias persuasivas o demostrativas abrirán el estudio de la necesidad y el alcance de lo que denominamos lo extradiscursivo. Los juegos serán, entonces, juegos de la verdad en los que se tratará de decir la verdad. Esta cuestión que desborda lo que nos ocupa deja, sin embargo, el asunto donde no ha de olvidarse.

El decir se debate en una consideración de la verdad cuya esencia es la libertad. Si hablamos de modos y procedimientos retóricos es porque versan «sobre aquellas cosas que a menudo pueden ser de otra manera» 17 , lo que nos insta a un análisis que el pensar $-\mathrm{y}$ quien piensa- hace de los dominios que no son estricta y supuestamente suyos, a la necesidad de reinterrogar las evidencias y los postulados, de sacudir los hábitos y costumbres, las maneras de hacer y de pensar, de disipar las familiaridades admitidas, de retomar las medidas de las reglas y de las instituciones. Y, a partir de esa problematización, «participar en la formación de una voluntad política (en la que tiene su papel de ciudadano que desempeñar y que jugar)»18. El sujeto es una forma no siempre idéntica a sí misma, una forma de relación, y las relaciones deben ser analizadas. Hay diferentes formas de ser sujeto.

17 Aristóteles, Retórica, 1357a 15.

18 Michel Foucault, «Le souci de la vérité», DE, t. IV, pp. 668-678, pp. 676-677. 


\section{UN ARTE DEL EXISTIR Y UN MODO DE VIDA}

La cuestión de 'quiénes somos' va unida, entonces, a la forma de constitución de una experiencia, en la que la relación consigo está vinculada a la relación con los otros, a la génesis, a la formación, a la historia. Por ello, hemos de comprender las técnicas de sí como operaciones que realizamos sobre nuestro cuerpo y nuestra alma, nuestros pensamientos, nuestras conductas y nuestro modo de ser, y que nos permiten transformarnos, a fin de alcanzar cierto estado de felicidad, de fuerza, de sabiduría, de perfección o de inmortalidad. Son técnicas para producir y transformar objetos, técnicas de sistemas y de utilización de signos, de sentidos, de símbolos o de la significación, técnicas de dominio ejercidas sobre los otros y técnicas de sí. En este contexto se habla de Sócrates como maestro de epimeléia heautoû: «Os preocupáis sin vergüenza de adquirir riquezas, famas y honores, les dice, pero no os ocupáis de vosotros mismos, no tenéis cuidado de la sabiduría, la verdad y la perfección del alma»19. La retórica y hermenéutica de sí comporta un verdadero arte de existir, la producción de modos de existencia, de nuevas posibilidades, de espacios de interacción, recreación e interpretación. Por eso, en la estética de la existencia, el decir verdadero se dice como modo de ser. Retórica y hermenéutica de sí, como formas de suspensión y de desprendimiento de sí, atienden a un modo de ser, a unas modalidades de la existencia, a un modo de vida. Si el conocimiento de sí ha eclipsado, en cierta medida, a la cultura del cuidado y la ocupación de sí mismo, nos vemos ahora convocados a una tarea que la palabra 'generosidad' puede preservar. 'Ser de buen origen' no consiste en remitir aristocráticamente cuanto somos y hacemos a la coartada de algo ya previamente dado, un lugar definido. El origen se expande en su quehacer original y, en efecto, origina algo otro. Limitar el horizonte de nuestra existencia a lo que ya ocurre y tratar de explicarlo por la remisión a algo otro ya previamente dado, como si pensar fuera comentar, cierra las puertas a la verdadera tarea de la interpretación como interpretación de sí mismo. Para ello precisamos -ellos también, en su carácter irreductible, nos precisan- de los otros, del otro 20 .

19 Platón, Apología de Sócrates, 29e.

20 No hablamos simplemente de la necesidad de los otros, sino de su intervención en nuestra efectiva concreción. Ellos nos precisan. Es su existencia y presencia la que impide que zanjemos lo que somos y decimos. Eso nos ha permitido hablar en otro lugar de 'la retórica del con quien' y ensayar una lectura de ciertas claves, desde esta perspectiva. La peroratio, por ejemplo, no cierra las posibilidades de otras palabras, las abre, las requiere, una vez que se reconoce que el auditorio no es puro receptor. El 
La tarea de la interpretación es también tarea del cuidado de sí, atención a las relaciones de fuerza y a las estrategias sociales. Necesitamos otras palabras, las palabras de los otros, las palabras del otro, las palabras de lo otro y lo otro de las palabras, el otro. Dotarnos de una verdad que no poseemos ni conocemos, una verdad que nos habita, es ser capaces del arrojo del aprender, en un ejercicio permanente. Si el sujeto es forma y forma de relaciones, hay 'modos' de constituirnos como sujetos. Tal vez, hemos perdido los modos, deambulamos sin arte de la existencia, sin técnicas de vida. La retórica y hermenéutica de sí convoca a experimentarse, a ensayarse, a una búsqueda práctica de otro modo de vivir, a una estilización de la existencia en la que la insurrección adopta la forma de una resistencia. Y resistir es también flanquear la línea para crear zonas donde «sea posible residir, vivir en ella, con ella, cuestión de vida o muerte» 21 . Ejercer el poder sobre uno mismo, autoafectarse, es también una manera de crear modos de existencia e inventar posibilidades de vida. El cuidado de sí puede llegar a suscitar «acontecimientos, aunque sea mínimos, que escapen al control, hacer nuevos espaciotiempos, aunque su superficie o su volumen sean reducidos»22. La creación de nuevas formas de vida, de relaciones, de amistad, en la sociedad, el arte y la cultura tienen lugar a través de nuestras elecciones y decisiones. Este eligere lee de otra manera, lucha inmediatamente, provoca todo un conjunto de intensidades de vida no sujeta a un control preestablecido.

La cuestión resulta un desafío. Se trata de 'desarrollar un modo de vida', 'una manera de ser aún improbable', que hay que inventar. La transformación es prácticamente una conversión. Arma el sujeto de una verdad que no conoce, y esa verdad aprendida y ensayada no es una verdad concedida de antemano, previamente establecida. Requiere más de argumentos que de demostración. Argumentos convincentes, adecuados, convenientes (que no equivale a 'de conveniencia', sino pertinentes, también en lo común, susceptibles de un acuerdo, siquiera consigo mismo). El sentido se ofrece en la ejecución. Con ello, la apropiación se

\footnotetext{
‘epílogo' se presenta como lugar de encuentro. El 'decoro' es también el de no clausurar la cuestión, el de propiciar una actitud de escucha. El vir bonus que cuida de sí, tiene la virtud de incorporar-que es un hacerse cargo y acoger- la alteridad en sus palabras. $C f$. «Pliegues y repliegues de la retórica (Hacia una retórica de sí mismo)», en T. Albaladejo, E. Del Río y J. A. Caballero (eds.), Quintiliano. Historia y actualidad de la retórica, Calahorra, Instituto de Estudios Riojanos / Ayuntamiento, 3 vols., 1998, vol. I, pp. 383-404.

21 Gilles Deleuze, Pourparlers (1972-1990), París, Minuit, 1990, p. 151 (trad. cast. Valencia, Pre-textos, 1995, p. 179).

22 Ibid., p. 239 (trad. cast. p. 276).
} 
presenta como autoconfiguración, más como objetivación y conformación que como representación. El arte de la existencia asume que lo que existe no agota todos los espacios. Reabrir la cuestión de 'a qué se puede jugar y cómo inventar un juego' exige ponerse a uno mismo en juego. Con ello se introduce una diversificación diferente de las ya tópicamente establecidas, que no se agota en la de las clases sociales, las diferencias de profesión, o los niveles culturales, una diversificación que sería también una forma de relación, y que sería el «modo de vida»23.

Así se comprende que el asunto no sea el de interpretar la vida, como si ella se enfrentara a la tarea de un sujeto presto a emprenderla; en efecto, a emprenderla con la vida. La unidad del quehacer con lo que se considera es el reconocimiento de la mutua pertenencia del hacer al ser del que hace y de lo que se hace. Lo que nos mueve no son motivos conductores previamente establecidos. Es preciso motivar desde posibilidades concretas dadas y abiertas, desde modos de vida que pueden vivirse y que, sólo en esa medida, lo son tales. El existir únicamente se da en cuanto estar en marcha en sí mismo hacia el existir. Ante este modo de ser de la hermenéutica, ha de tomarse en cuenta el estar en marcha y abrirle camino en atención al ser-posible. «Sin esta perspectiva, la hermenéutica misma no pasará de ser una trivialidad [...] La hermenéutica no es para nada filosofía, sino algo estrictamente previo y provisional, lo que, desde luego, es su naturaleza más propia: no se trata de acabar lo antes posible con ella, sino de mantenerse en ella el mayor tiempo posible. Estamos en la actualidad tan faltos de enjundia que ya ni somos capaces de soportar una cuestión: cuando uno de los curanderos filosóficos no tienen respuesta, se acude al siguiente. Esa demanda hace que la oferta crezca. En lenguaje popular, a eso se le llama 'un interés creciente por la filosofía’» 24 .

El olvido es el de esta mutua pertenencia del preguntar a lo preguntado, el de la pregunta constitutiva de lo que hay como cuestión. Eso muestra que la interpretación no es un recurso complementario del conocimiento, «el conocimiento del mundo y la orientación en él implican siempre el momento de la comprensión... y de ese modo se puede evidenciar la universalidad de la hermenéutica. La lingüisticidad funda-

23 Michel Foucault, «De l'amitié comme mode de vie», DE, t. IV, pp. 163-167. Foucault considera que un modo de vida «puede dar lugar a relaciones intensas que no se parecen a ninguna de las que ya están institucionalizadas», «puede dar lugar a una cultura, a una ética» (p. 165).

24 Martin Heidegger, Ontología. Hermenéutica de la facticidad, Madrid, Alianza, 1999, p. 39. 
mental de la comprensión no significa obviamente que la experiencia del mundo se efectúe como lenguaje y en el lenguaje, de modo exclusivo. Son de sobra conocidos todos esos recogimientos, enmudecimientos y silencios pre- y supralingüísticos, en que se expresa el impacto directo del mundo ¿y quién negará que hay unas condiciones reales de la vida humana, que se da el hambre y el amor, el trabajo y el poder, que no son discurso ni lenguaje, sino que miden, a su vez, el espacio dentro del cual puede producirse el coloquio y la escucha mutua? Eso es tan evidente, que son justamente esas formas previas de pensamiento y de lenguaje humano las que reclaman la reflexión hermenéutica» 25 . De ahí que la experiencia de nuestra constitución como mortales en la palabra sea también la experiencia de los límites del lenguaje. Precisamente por ello el lenguaje se desenvuelve en el elemento de la conversación 26 , porque el modo de ser de cuanto es se nos revela hablando de ello 27 , y porque no hay acceso a la verdad sin transformación de nuestro modo de ser, lo que implica el lenguaje, su fuerza generativa y creadora 28 . Pero la primacía de la 'lingüisticidad' de nuestra experiencia exige el reconocimiento del carácter de mundo intermedio del lenguaje, frente a las ilusiones de la autoconciencia y frente a la ingenuidad de un concepto positivista de los hechos como si fueran la verdadera dimensión de una realidad exenta de interpretación. Si ello comporta que lo que se expresa se ve desbordado por lo mentado en un lenguaje, resulta asimismo desconsiderado reducir y remitir los textos a lo que ya, supuestamente, uno mismo o el mundo ya es. Son puntos de referencia ineludibles pero que abren el ámbito de lo cuestionable, de la pluralidad de posibilidades, fases abstractas en tanto que aisladas y fijadas. Y hace falta que hablen de nuevo.

Quizá, por ello, la retórica y hermenéutica de sí puede llegara ser también un modo de vida que se hace cargo de la cuestión en que consiste la existencia, un modo de llevar una vida filosófica, aquél que considera decisiva la cuestión de ‘¿cómo se vive una vida filosófica?’, cuestión abierta que comporta y exige una determinada manera de vivir. Si a eso se acompaña del cuidado y del cultivo de sí en el arte de la existencia, de la belleza de la propia vida, decir bien, bien decir, decir de ver-

25 «Selbstdarstellung Hans-Georg Gadamer», WM II, pp. 479-495, pp. 496-497 (trad. cast. VM II, pp. 375-402, pp. 391-392).

26 Hans-Georg Gadamer, «Sprache und Verstehen», WM II, pp. 184-198, p. 198 (trad. cast. VM II, pp. 181-194, p. 194).

27 Hans-Georg Gadamer, «Was ist Wahrheit?», WM II, pp. 44-56, p. 56 (trad. cast. VM II, pp. 51-62, p. 62).

28 Hans-Georg Gadamer, «Wie weit schreibt Sprachen das Denken vor?», WM II, pp. 199-206, p. 206 (trad. cast. pp. 195-201, p. 201 ). 
dad y decir verdad resulta una actividad exigente que no es otra vida que la de vivir de otra manera, hasta el extremo, quizá, que otra manera que lo que llamamos vivir. Por eso, la pluralidad de veces y de voces no se reduce a la proliferación en que uno mismo consiste. También lo es del modo de proceder que desplaza el discurso uniforme de un sujeto que, supuestamente, tiene la palabra y, desde sí, se dirige a otro.

«El 17 de diciembre de 1976, en el plató de 'Apostrophes', excepcionalmente instalado en el Museo del Louvre, Bernard Pivot se sorprende: "Entonces, ¿realmente no quiere usted hablar de su libro?" "No -responde Michel Foucault-; al principio uno escribe un poco las cosas porque las piensa, pero también para dejar de pensar en ellas. Acabar un libro también es estar harto de un libro. Mientras uno sigue amando un poco su libro, va trabajando en él. Cuando uno ha dejado de amarlo, también deja de escribirlo". Y además, sobre todo: hay otro libro más digno de interés: "Un libro como los que me gustan a mí; hecho con fragmentos de la realidad, de cosas que se dicen, de gestos, de documentos, de tristezas, de miserias..." ¿Su autor? No busquen más» 29 . Se produce una sintonía supuestamente silenciosa que es la de la escritura de un texto y de una vida, la de los hypomnémata (libros de cuentas, registros públicos, cuadernos individuales que servían de ayuda-memoria y, posteriormente, libros de vida, guías de conducta que consignaban citas, fragmentos de obras, ejemplos y acciones de las que se había sido testigo o cuyo relato se había leído, reflexiones o razonamientos, una memoria material de las cosa leídas, oídas o pensadas que se ofrecían a la relectura y meditación o como depósito para la escritura) ${ }^{30}$ y la del sí mismo como tarea.

Hablar a la vez en varias veces y con varias voces, hasta el punto de refutarse y de ponerse en situación crítica es también inscribirse en la boca de quienes nos escuchan, no un hablar por su boca, sino un ser hablado por lo que se hace oír. La actio o la pronuntiatio son gestos, energía textual comunicativa, la entrega del cuerpo al espacio público. Hablar bien es actuar sobre sí mismo, obligarse al cuidado, a lo minucioso, al discernimiento. Y hacerlo desde una necesidad y una disposición a dejarse decir y a despojarse. Si ha de evitarse 'producir efectos', sin más, mediante un lenguaje teatral, o las excesivas inflexiones de voz, es en la medida en que el tono y el ritmo, y la articulación, responden a la valentía y a la energía que comporta el inscribirse en el decir, lejos de una actitud altanera. Dicha inscripción no se reduce a la descripción de

29 Didier Eribon, Michel Foucault, Barcelona, Anagrama, 1992, p. 342.

30 Michel Foucault, «L'écriture de soi», DE, t. IV, pp. 415-430, pp. 418 y ss. 
lo que se ve, y no sólo en nombre de la sospecha, sino para abrir causas, explicaciones y complicaciones. Y abrir es un ir y venir, también el de los afectos, el tacto de los adjetivos y su modo de acompañar.

Estos breves ejemplos subrayan que se requiere, además de saber lo que se ha de decir, decirlo como se debe ${ }^{31}$. Y tal deber llama a un estilo, a un modo de ser y de vida que ciertamente atiende al modo de ser del auditorio. Pero es la mutua pertenencia a ese concreto modo la que nos autoriza (aquí se modifica la noción de autor, ahora también como resultado) a hablar con y desde quienes nos escuchan. Podrían, por tanto, estudiarse todos los procedimientos retóricos como modos de proceder de quien, quizá, es ausente en cierto sentido también para sí mismo. Se habla así desde lo que se carece, porque se busca, dado que se necesita. No siempre, ni en las mejores ocasiones, se habla de lo que se posee. Cabe hacerse desde ello, con ello. Incluso en tales casos, es preciso hacerlo con otros. Y así, el auditorio universal se presenta en la universalidad del quehacer hermenéutico, el que se abre a las diferencias, el que considera que es posible el acuerdo. En efecto, el debate entre «el poder de la buena voluntad» y «la buena voluntad de poder» está abierto 32 . En todo caso, no siempre resulta más fácil comprenderse a uno mismo que a alguien otro. Ni siquiera uno es ya, sin más, sí mismo. Tal vez, comprender sea también el nombre de esa tarea de comprenderse, de un llegar permanente, que es tanto como no llegar nunca del todo. Algo así ocurre con la palabra. Pero el aspecto hermenéutico no se reduce, como señalamos, al arte, a la historia, ni al trato con los 'textos', ni a la experiencia, abarca «todo aquello que puede ser objeto de acuerdo mutuo» 33 , acuerdos de uno mismo, acuerdo consigo y con otros.

Quizá lo expuesto, en la tensión por involucrar el sujeto de la enunciación con el sujeto de la conducta -en una determinada lectura de la parresía- permita una consideración que no tiene carácter final, sino

31 Aristóteles, Retórica, III, 1403b 15.

32 Véase Hans-Georg Gadamer, «Dennoch: Macht des guten Willen», réplica oral a las tres preguntas de Derrida, en Text und Interpretation, Múnich, Fink Verlag, 1984, pp. 59-61. El título («Pese a todo, el poder de la buena voluntad») fue propuesto por Philippe Forget para dicha edición. Trad. cast. en Antonio Gómez Ramos (ed.), Diálogo y deconstrucción. Los límites del encuentro entre Gadamer y Derrida, pp. 4547. $C f$. Jacques Derrida, «Bonnes volontés de puissance. Une reponse à Hans Georg Gadamer», Revue Internationale de Philosophie, $\mathrm{n}^{\circ}$ 151, 1984, pp. 341-343. Este título «Las buenas voluntades del poder. (Una respuesta a Hans Georg Gadamer)» fue asimismo propuesto por Philippe Forget para la edición alemana citada, pp. 56-58. Trad. cast. en Diálogo y deconstrucción, op. cit., pp. 43-44.

33 «Selbstdarstellung Hans-Georg Gadamer», op. cit., p. 497 (trad. cast. p. 192). 
que abre todo principio. En cualquier ocasión, antes de dirigirse al público, conviene, siquiera simbólicamente, retirarse y guardar, al menos, un minuto de silencio, abrir un tiempo entre vivos por los que no están ya o no están todavía, por quienes se fueron, se irán, se van, por quienes aguardan, por quienes consistimos en un permanente irnos. Es un estar con ellos. Si hemos oído destacar como partes de la retórica la intellectio, la inventio, la dispositio, la elocutio y la memoria, hemos de considerarlas como verdaderas operaciones. Si actualmente se ofrece un mayor alcance, que el habitualmente otorgado, a la intellectio ${ }^{34}$, en tanto que comprensión de la situación retórica, o como conjunto de conocimientos y experiencias, el minuto de silencio es más que un gesto para con esos otros (quiénes son, qué les trae, qué común espera de la palabra, qué mutua pertenencia nos reúne en un espacio). Es más que el silencio por los otros, es el silencio de los otros en uno, el silencio que nos da que hablar. Ese minuto paradójicamente descoyunta el tiempo y espacializa la intervención en un retiro que impide el acceso inmediato. El afán de persuadir y convencer no es el único objetivo de la palabra. Si la inventio y la dispositio buscan tramar y lograr un referente, no por ello son mera proyección, son producción, hallazgo de asuntos verdaderos o verosímiles, aquéllos que le hacen a alguien apto. Al tejer un texto, uno labra un espacio con alguien en el que poder llegar a ser, tal vez, diferente. En ese mundo espacializado, la tradición se nos transmite como un depósito de posibilidades y sobrevivirse adopta la forma de un retiro, un retirarse en sí mismo, una suspensión, un desprendimiento, que es el de la generosidad de un hablar de verdad. En los que nos esperan, arriban quienes ya supuestamente no están. La tradición es el ocio de la espera fecunda, terreno de la recreación. Antes de hablar, un minuto de silencio por lo que se nos va y se nos viene en las palabras que no son de uno.

En realidad, habitar el tiempo de otro modo responde a una cierta intempestividad, a un cierto cultivo del ocultamiento, a la posición de una escucha, de un estar dispuesto a decir y dejarse decir, a la apertura de unos terrenos de ocio y recreación en los que ya la primera palabra se inscribe en lo que se viene diciendo, es respuesta, reclama responsabilidad. Ese retiro en sí no es simple alejamiento, es otra forma de cercanía,

$34 C f$. por ejemplo, Francisco Chico Rico, «La intellectio en la Institutio Oratoria de Quintiliano: ingenium, iudicium, consilium y partes artis», en Quintiliano: Historia y actualidad de la Retórica, op. cit., vol. II, pp. 493-502. De la intellectio dependería «lo constituyente de discurso y lo no constituyente de discurso, lo poiético y lo práctico, en virtud del componente estructurador de la textualidad y de la comunicación retórica que es el decorum o aptum» (p. 502). 
la que no reduce lo que se dice a lo que uno dice. Tal distancia, que no es la que se toma, sino la que se cultiva, la que se recorre y la que se preserva, es también el reconocimiento de la propia diferencia. Entonces, la intervención adopta la forma de una conversación, incluso antes de que se oiga hablar a los otros, que desde el principio se ven llamados asimismo a tomar posición, convocados a dejarse decir. No estamos sino ante un modo más de establecer relaciones de diferenciación, de creación, de innovación 35 .

Estar dispuesto a luchar con alguien (posición agónica) no significa necesariamente hacerlo contra él, enfrentado a su decir (posición antagónica), como si uno sólo pudiera pensar frente a lo ya pensado, en lugar de hacerlo con ello. La coimplicación de quien habla con aquellos con quienes habla, en la mutua pertenencia común de lo que a alguien le hace hablar con lo que al otro le hace escuchar, insta a ambos, en cada caso, a la lucha del oír y del decir. Esta forma de proceder es una más, y se inscribe en otros modos de acción. De ahí que ciertas relaciones de amistad o determinadas comunidades de amigos, algunas singulares experiencias o ciertas tomas de posición sobre asuntos concretos, o irreductibles resistencias cotidianas o solidarias se presenten como intensidades de vida que vinculan ese hablar que recorre la distancia entre lo que se dice y lo que se hace y retornan de lo uno a lo otro, en una parresía en acción, que fecunda otro modo de ser de lo político.

La relación entre la retórica y la hermenéutica no se reduce a la que cabe establecer entre dos disciplinas. Cuando atendemos a la retóricahermenéutica de sí nos hacemos cargo de que los modos de constitución y de producción no están desvinculados de los modos de interpretación. Se precisa una poética de sí. La diferenciación, la creación y la innovación son también las de los procedimientos que son efectivas prácticas de libertad.

35 Michel Foucault, «Une interview: sexe, pouvoir et la politique de l'identité», DE, t. IV, págs 735-746, p. 739. 